Allpanchis, año XLVIII, núm. 88. Arequipa, julio-diciembre de 2021, pp. 185-216.

ISSN impreso 0252-8835 / ISSN en línea 2708-8960

DOI: https://doi.org/10.36901/allpanchis.v48i88.1322

\title{
dossier
}

\section{La observancia del silencio en las Clarisas de Antigua Fundación de Santiago de Chile (siglos XVII-XIX)}

\author{
Alexandrine de LA TAille-Trétinville \\ Universidad de los Andes (Santiago, Chile) \\ adelataille@uandes.cl \\ Código ORCID: 0000-0002-6919-1138 \\ Marcelo AguirRe Durán \\ Universidad de los Andes (Santiago, Chile) \\ marceaguirred@gmail.com \\ Código ORCID: 0000-0002-6282-5847
}

\section{RESUMEN}

El siguiente artículo analiza la observancia de la Regla de Santa Clara de Asís por parte de las religiosas del Monasterio de Santa Clara de Antigua Fundación (Santiago de Chile). Específica- 
mente, en este texto proponemos una revisión de la práctica cotidiana del silencio intramuros, a fin de verificar de qué modo la observancia de la Regla de Santa Clara presenta variantes propias en Chile con respecto a Hispanoamérica, considerando la distancia temporal y geográfica de sus orígenes. Para ello, exploramos la relación de estas monjas con la jerarquía eclesiástica de la diócesis a partir, principalmente, de una selección de visitas pastorales y de sínodos de Santiago durante los siglos XVII, XVIII y XIX. Este estudio colabora con el conocimiento de la Orden de Santa Clara en Chile pues, hasta ahora, no existe una obra monográfica que abarque, bajo la perspectiva de las prácticas de los tradicionales votos monásticos, los cuatro siglos de historia de esta comunidad de mujeres.

Palabras clave: clarisas, Regla de Santa Clara de Asís, diócesis de Santiago de Chile, visitas pastorales, silencio

\title{
The observance of silence in the Poor Clares of Ancient Foundation of Santiago de Chile (1 $17^{\text {th }}-19^{\text {th }}$ Centuries)
}

\begin{abstract}
The following article analyses the observance of the Rule of Saint Clare of Assisi by the nuns of the Monastery of Saint Clare of Ancient Foundation (Santiago de Chile). Specifically, in this text we propose a review of the daily practice of silence inside the walls. To do this we explore the relationship of these nuns with the hierarchy of the diocese, from a selection of Pastoral Visits and Synods of Santiago during the seventeenth, eighteenth and nineteenth centuries. This study contributes to the knowledge of the Order of Saint Clare in Chile because, up to now, there is no monographic work covering the history of four centuries of this community of women.
\end{abstract}

Keywords: Poor Clares, Rule of Saint Clare of Assisi, diocese of Santiago de Chile, pastoral visits, silence 


\section{INTRODUCCIÓN}

LA FORMA DE VIDA IMPUlSADA POR SANTA Clara de Asís (11941253) ha tenido una gran importancia en la formación de la vida y de la práctica conventual en la América hispana desde la época del descubrimiento y conquista y, muy especialmente, durante el período virreinal. Por medio del ejemplo de la clausura dentro de la ciudad, esta fundadora sintetiza el modelo de vida de san Francisco de Asís y otorga las características inherentes a la condición religiosa femenina del siglo XIII, poniendo un especial acento en la renovación de la santa pobreza, eje de toda la espiritualidad franciscana. A pesar de que es ella misma quien considera al Poverello como el verdadero fundador de las Hermanas Pobres o Segunda Orden, la regla profesada por la asceta itálica contempla algunas variantes con respecto a la masculina, las que resultan relevantes en la transmisión de este ideal de clausura religiosa que terminará implementándose, de manera particularmente extendida, en los territorios ultramarinos del reino de Castilla a partir del siglo XVI.

En este artículo proponemos una descripción, análisis e interpretación de la peculiar observancia del silencio — aspecto esencial de la vida monástica cristiana - tras los muros del Monasterio de las Clarisas de Antigua Fundación de Santiago de Chile, entre los siglos XVII y XIX, con el objeto de verificar cómo la fidelidad a la Regla de Santa Clara presenta variantes propias en Chile con respecto a Hispanoamérica, considerando la distancia temporal y geográfica de sus orígenes. El estudio se fundamenta en fuentes que no han sido consideradas por la historiografía a la hora de abordar dicha orden femenina. Solamente historiadores nacionales como Armando de Ramón, Gabriel Guarda e Isabel Cruz de Amenábar han recurrido al archivo de las clarisas con diversos fines. ${ }^{1}$ En este caso, el trabajo

1 En el caso de Armando de Ramón, nos referimos al libro Orígenes de la vida económica chilena. 1659-1808 (1982). En su amplio trabajo historiográfico, Gabriel 
se ha concentrado en un corpus de fuentes documentales que podemos reunir en dos grupos: a) las visitas pastorales realizadas por los obispos al convento, las que se encuentran en el Archivo Histórico de la Orden; y b) los sínodos diocesanos de los obispos Bernardo Carrasco y Saavedra y Manuel de Alday.

Las clarisas chilenas fueron consideradas díscolas por sus contemporáneos debido, principalmente, a las constantes amonestaciones de las autoridades civiles y eclesiásticas por las faltas a la observancia de sus constituciones, según señalan las visitas pastorales que se custodian en el archivo y los libros de cuentas, puesto que detallan el consumo de alimentos y otros gastos que no se condicen con la ascesis de la regla. Ellas han constituido un ejemplo recurrente para la historiografía local, ${ }^{2}$ cuando se trata de demostrar en qué medida las reglas de vida conventual se mitigan o adecuan,

Guarda ha incursionado en el Archivo de las Clarisas de Antigua Fundación, especialmente en su última monografía titulada La Edad Media en Chile. Historia de la Iglesia. Desde la fundación de Santiago a la incorporación de Chiloé. 1541-1826 (2016). A su vez, Isabel Cruz de Amenábar ha abordado estas fuentes archivísticas en su obra La fiesta. Metamorfosis de lo cotidiano (1995). En esta misma línea, la documentación de las clarisas ha sido estudiada dentro de la reciente publicación de Isabel Cruz de Amenábar, Alexandrine de La Taille y Alejandra Fuentes González: Cerámica perfumada de las monjas clarisas. Desde Chile hacia el mundo. Oficio, terapéntica y consumo (2019). Por otra parte, la obra de Alfredo Palacios Roa, Breve historia del Monasterio de Santa Clara de Antigua Fundación (1567-1913) (2017), se trata de un trabajo concreto sobre esta orden religiosa, pero de carácter más general. Él se centra en el vínculo de las monjas con los terremotos y utiliza, principalmente, fuentes relevantes del Archivo General de Indias, pero no necesariamente documentos internos del monasterio. En este sentido, nuestro trabajo puede constituir un aporte y un complemento.

2 Un miembro de la expedición Malaspina, a finales del siglo XVIII, constata la presencia de cuatrocientas personas en el Monasterio de Santa Clara de Antigua Fundación (Sagredo y González, 2004, p. 474). Armando de Ramón, en su estudio preliminar a la Relación Autobiográfica de Úrsula Suárez, se refiere en general al panorama de los monasterios femeninos de la época, señalando los de las clarisas como ejemplos de la mitigación de la regla (Suárez, 1984). Recurrentes excesos a la regla han sido descubiertos, analizados e interpretados por Alejandra Fuentes González en su tesis doctoral, presentada en 2019, en la Universidad de 
según corresponda, a la realidad de la América española colonial y republicana. Sin embargo, y pese a la relevancia histórica de esta comunidad religiosa, ya sea por su antigüedad, por el número de mujeres que albergaba el monasterio, por la producción de cerámica y repostería o por los vínculos culturales y económicos con la sociedad de la época, aún no existe una obra monográfica que abarque la historia general de la Orden de Santa Clara en Chile. Los mayores aportes han sido dados gracias a la aproximación de Alfredo Palacios Roa, más general y que no considera un estudio en detalle del archivo, además del estudio de las cerámicas perfumadas; en otras palabras, no hay un trabajo monográfico que indague en los aspectos concretos sobre las prácticas comunitarias intramuros. Por el contrario, no ocurre lo mismo con las religiosas contemplativas de otras órdenes y comunidades, cuyas historias sí han sido reconstituidas gracias a los esfuerzos de diversos historiadores o iniciativas propias. ${ }^{3}$ Por esto, siguiendo la línea de investigación recientemente iniciada, el presente trabajo constituye una aproximación al estudio de esta comunidad y a su labor en el contexto histórico local. ${ }^{4}$

Ahora bien, los orígenes de la regla se encuentran en la forma de vida que san Francisco entregó a santa Clara una vez que ella tomó la resolución de apartarse del mundo y de retirarse al emblemático Convento de San Damián, en 1211, para vivir de acuerdo con las enseñanzas evangélicas. La historia de dicha regla es comple-

los Andes: Entre la oración contemplativa y el trabajo de sus manos: clausura femenina y prácticas laborales en el Monasterio Antiguo de Santa Clara de Santiago, 1678-1825.

3 Algunos ejemplos son: Peña Otaegui, 1951; Prieto, 1911; Muñoz Olave, 1926; Fontecilla Larraín, 1943. Algunas órdenes como el Carmelo Descalzo han emprendido desde dentro la tarea de publicar su historia; véase, por ejemplo: El arca de tres llaves. Crónica del Monasterio de Carmelitas Descalzas de San José (1989). Para la vida conventual en Chile en los siglos XVI, XVII y XVIII, consúltese Millar y Duhart, 2005.

4 Dos recientes publicaciones constituyen un esfuerzo en este sentido: Palacios Roa (2017); Cruz, de La Taille y Fuentes González (2019). 
ja; luego de que la normativa de san Francisco fuera adaptada por la doncella de Asís, teniendo en consideración las observaciones del cardenal Hugolino (1245), fue aprobada en 1253 por el papa Inocencio IV. ${ }^{5}$ Posteriormente fue modificada para el monasterio de la beata Isabel de Francia (1259), variante que fue aprobada por el papa Urbano IV (1263) (Omaechevarría, 1970, pp. 16-19); es esta la que se aplicó en Chile.

Con la Regla de Santa Clara algunas prácticas de vida cristiana tales como la pobreza y la clausura, que forman parte de la tradición de la Iglesia, adquieren una dimensión y un dinamismo nuevos. Por una parte, la regla se hace cargo de la tradicional diferenciación entre hombres y mujeres, la que deja en evidencia la renuncia a la acción apostólica femenina y da cabida a la predicación propia de los varones, determinando que las religiosas vivan, idealmente, en una completa separación del mundo. Asimismo, se establece como norma que las monjas deben encerrarse de por vida dentro del monasterio, lo que constituye una diferencia de la norma benedictina, la cual estipulaba que, con el permiso de la abadesa, las religiosas sí podían salir de la clausura conventual bajo ciertas circunstancias particulares (Iriarte, 1979, caps. 1 y 2).

Junto con lo anterior, cabe señalar que a partir de los estatutos dictados por el cardenal Hugolino en 1219, se instituye para las Hermanas Pobres la novedosa obligación de la clausura como un voto añadido a los ya tradicionales tres consejos evangélicos, es decir, pobreza, castidad y obediencia. De allí que las Damas Pobres sean conocidas, en sus comienzos, como las «encerradas de San Damián» (Omaechevarría, 1970, p. 213).

Con esto, la clausura ayudaba a la vida contemplativa tanto por la prohibición de las monjas de salir del monasterio (clausura activa o interna), como por la imposibilidad de que ingresaran personas extrañas a la orden, lo que propiciaba un silencio y una quietud de

5 Cf. Rodríguez Núñez, 1996, pp. 90-92. 
espíritu aconsejados por los grandes fundadores de Asís. En otras palabras, «la contemplación de Clara y sus sores se afirmaba como elemento determinante en la gran obra franciscana» (Omaechevarría, 1970, p. 10).

Para las comunidades femeninas que siguen esta regla, santa Clara es el modelo que la encarna en su propia vida. Los relatos hagiográficos destacan sus estrictos ayunos, sus mortificaciones corporales y sus largas horas dedicadas a la oración, motivo por el cual se encierra en San Damián «en un silencio sin fin» (Lainati, 2004, p. 80), a imitación de la Virgen María, con el fin de acceder a un rango superior de contemplación y de escucha de lo divino. ${ }^{6}$

En este sentido, la normativa del silencio se plantea en la regla en los siguientes términos:

Desde la hora de Completas hasta Tercias las hermanas guarden silencio, excepto las que sirven fuera del monasterio. Guarden también silencio siempre en la Iglesia, en el dormitorio, en el refectorio solamente cuando comen; excepto en la enfermería, en la que podrán hablar siempre las hermanas con discreción para recreo y servicio de las enfermas. Puedan también siempre y en todas partes insinuar brevemente y en voz baja lo que fuere necesario. ${ }^{7}$

Asimismo, la regla especifica que si «alguna persona [extraña], religiosa o seglar o de cualquier dignidad, quisiere alguna vez hablar con alguna de las monjas», debe contar con la autorización de la abadesa. La monja interesada debía ir al locutorio acompañada por, al menos, otras dos, quienes oirían todo lo que allí se dijera (Omaechevarría, 1970, pp. 221-222).

6 Para una aproximación al valor de las hagiografías y su estudio en la América colonial, véase Millar (2013). Desgraciadamente, el archivo de las clarisas antiguas no guarda ningún manuscrito o documento hagiográfico.

7 Omaechevarría (1970, pp. 261-262). 
En los orígenes de la orden la observancia del silencio parece ser un aspecto respetado estrictamente, tal como lo señalan algunos testigos quienes, dando noticia de lo visto en San Damián, han afirmado que: «hasta tal punto se han habituado a callar algunas, que, cuando se ven forzadas a hablar, apenas si recuerdan [...] las palabras que deben emplearse» (Omaechevarría, 1970, p. 44).

Es precisamente este silencio el que permite a las Damas Pobres dedicarse por completo a un régimen de vida contemplativo, en cuanto enclaustradas y esposas de Cristo en un sentido místico, lo que presupone un compromiso íntimo de la reflexión metafísica que se introduce en lo sobrenatural a partir de la experiencia de lo natural, como un acto de amor y de búsqueda de la Verdad (Rassam, 2017, p. 27).

La Regla de Santa Clara, ejemplo de renovación de la clausura del siglo XIII, se propagó rápidamente por Europa y también, por extensión, llegó a la América hispana, lugar en donde tuvo un rol primordial en la instauración de la vida religiosa femenina del Nuevo Mundo, de modo particular a partir del siglo XVI.

\section{Las Clarisas EN CHILE}

Las Clarisas de Antigua Fundación son las primeras monjas establecidas en el Reino de Chile, y la cuarta orden femenina que se funda en la América española. ${ }^{8}$ En 1567 se constituye un beaterio en la ciudad de Osorno, bajo la advocación de Santa Isabel de Hungría, dirigido por Isabel de Palencia e Isabel de Landa; es por eso por lo que se les conoció bajo el nombre de las Isabelas, de quienes no se tiene mayores antecedentes (Cruz, de La Taille y Fuentes, 2019,

8 Hasta el último tercio del siglo XVII no existió en Chile otra modalidad de vida religiosa femenina que no fuese la conventual de reclusión y clausura. 
pp. 66-67). Luego del desastre de Curalaba de $1598,{ }^{9}$ hito de la historia social chilena, estas mujeres emprendieron una azarosa travesía, dirigiéndose a la localidad de Castro (Chiloé) y a la isla Quiriquina, para llegar a Santiago en 1604, habiendo pasado por San Francisco del Monte. En la capital del Reino se establecieron en La Cañada y decidieron seguir el camino de la clausura según el modelo dictado por santa Clara, cambiando en este momento su nombre por el de clarisas. ${ }^{10}$ Profesaron, entonces, la segunda regla de Urbano IV, tal como se ha indicado anteriormente, siguiendo el espíritu franciscano de contemplación (La provincia eclesiástica chilena, 1895, p. 358; Triviño Monrabal, 2011, p. 435). ${ }^{11}$ Ya asentadas, las clarisas vieron cómo su monasterio se poblaba cuantiosamente durante el siglo XVII, no solo por monjas sino también por mujeres seglares tales como familiares, sirvientas, esclavas, donadas y educandas.

Dentro de las religiosas propiamente tales, existían - tal como en el resto de Hispanoamérica- dos categorías denominadas a partir de sus actividades y del hábito: las monjas de coro o de velo negro y las legas o de velo blanco. Las primeras provenían generalmente de la élite, podían pagar una dote más onerosa y al profesar

9 Hito de la Guerra de Arauco, el llamado Desastre de Curalaba fue un enfrentamiento entre el pueblo mapuche y los españoles a finales de 1598, el que terminó con el dominio de los primeros en la zona sur del país, más allá del río Biobío. Los indígenas sorprendieron a los peninsulares y dieron muerte al gobernador de Chile, Martín García Óñez de Loyola. Debido a este contexto de violencia y de hostilidad, las Isabelas - y las mujeres que las acompañaban en su vida de penitencia y de oración — abandonaron la ciudad de Osorno y se dirigieron hacia el norte.

10 Para una historia general del Monasterio de Santa Clara hasta 1913, véase Palacios Roa (2017). Esta obra es un estudio general. Como se comentó en la nota 1 , nuestro trabajo viene a ser un complemento ya que se basa en fuentes internas del Archivo de Santa Clara, las cuales no han sido consideradas en la valiosa publicación recién nombrada.

11 La Regla de Santa Clara fue aprobada en 1252 por Inocencio IV. Fue modificada por Isabel de Francia y por el cardenal Gaetano Orsini y san Buenaventura. Esta última variante fue aprobada por Urbano IV. 
se dedicaban, además de sus obligaciones propias en cuanto consagradas, a las labores intelectuales como, por ejemplo: lectura, escritura, copia de textos, registro de cuentas y anotaciones matemáticas, además de la redacción de correspondencia y de recetas medicinales y culinarias (la magnitud del archivo da cuenta de esto). Por ello disponían de celdas amplias y con diversas habitaciones que podían ser ocupadas por mujeres a su servicio, familiares o damas de compañía. Ellas tenían un lugar reservado en el coro, donde se rezaba diariamente en diferentes instancias el oficio divino, y podían votar en las elecciones de abadesas y ser elegidas para ocupar dicho cargo.

Por su parte, las hermanas legas pertenecían a familias menos acaudaladas y de origen más modesto. Si bien requerían de la dote para ingresar al claustro, su monto era menor; no tenían lugar en el coro ni derecho a voto. Sin embargo, el hecho de estar asociadas a las labores domésticas las hacía imprescindibles en los conventos multitudinarios. También, según los casos, contaban ellas mismas con personal de apoyo. Todas las religiosas, independientemente de su origen, ejercían un oficio normado según las constituciones y la tradición monástica femenina, tal como lo evidencian los libros de profesiones, donde se especifica que el costo de una dote para monja de coro es superior al de las religiosas de velo blanco. Las donadas constituían una categoría diferente, no eran religiosas ni tenían el deber de profesar la regla. Lo mismo ocurría con otras seglares, como parientes o damas de compañía de las consagradas. A este universo se debe agregar, además, a los sirvientes y esclavos, quienes podían ser hombres y mujeres.

Esta figura es común en la América hispana, como bien lo ha constatado la historiografía para los casos emblemáticos de México, Perú y Argentina. ${ }^{12}$ De este modo, la gran circulación de personas dentro de los muros conventuales condujo a la mitigación de la re-

12 Destacamos, especialmente: Lavrin (1993), Loreto López (2000), Arenas Frutos (2005), Van Deusen (2007), Burns (1999) y Fraschina (2010). 
gla en varios aspectos, siendo uno de ellos el cuidado y el resguardo del silencio en sus diversas dimensiones.

Las clarisas del Reino de Chile representan un caso más o menos extendido en la América Hispana. La gran cantidad de personas que habitaban el claustro —quinientas, aproximadamente- ${ }^{13}$ lo convierten en una suerte de «colmena humana», definición acertada que se ha aplicado a otros monasterios de Nueva España y del Virreinato del Perú y que puede extenderse, asimismo, para la situación del de Santiago (Martínez Cuesta, 1995, p. 581). ${ }^{14}$ El elevado número de personas y los vínculos con la ciudad se manifestaban en la afluencia de público a los locutorios, lo que perturbaba el silencio y propiciaba las relaciones con el ámbito exterior. Lo anterior se debía a las constantes visitas al locutorio por motivos religiosos, económicos o familiares, lo que significaba un problema más profundo: las monjas, tras los muros, nunca rompían con el mundo como había estipulado santa Clara y como señala la tradición de la Iglesia. Asimismo, el poder económico se contradice con el voto de pobreza y la misma vida cotidiana al interior de la clausura. ${ }^{15}$ Todo

13 Luego de un acucioso estudio de los libros de profesiones, de registros de dotes y de renuncias del siglo XVIII contenidos en el archivo, se concluye que en el convento conviven alrededor de unas sesenta u ochenta religiosas (de velo negro y blanco). Cada una de ellas estaría acompañada de, al menos, tres criadas, además de seglares de todo tipo, desde parientes hasta peones y esclavos. Es por esto por lo que se estima la cantidad de quinientas personas, aproximadamente. Véase: MCAF, vols. 24, 38, 56, 59, 89 y 96-100.

14 Esta expresión se refiere a los monasterios femeninos de Lima, Quito y México. «En el siglo XVII la Encarnación, Santa Clara, la Concepción y la Santísima Trinidad de Lima, Santa Catalina de Arequipa, la Concepción y Santa Clara de Quito, la Encarnación, Santa Clara y Jesús María de México, la Concepción de Guatemala y algunos otros monasterios se convirtieron en colmenas humanas con 800, 1.000 y hasta 1.300 mujeres» (Martínez Cuesta, 1995, p. 581).

15 En el estudio preliminar a la Relación autobiográfica de Úrsula Suárez (1666-1749), religiosa clarisa del Monasterio de Nuestra Señora de la Victoria, Armando de Ramón explica cómo se vivía al interior de los conventos y se refiere a la relajación de la regla (Suárez, 1984, pp. 71-72). Si bien el estudio del profesor De 
ello pone de manifiesto la existencia de constantes transgresiones a la regla, las que intentan ser controladas por la monarquía castellana y por las autoridades eclesiásticas a través de las visitas pastorales y de los sínodos locales.

\section{La práctica del silencio y Regla de Santa Clara: Registro y RELEVANCIA DE LAS VISITAS PASTORALES}

La llamada visita pastoral es una antigua institución eclesiástica y parte fundamental en la política administrativa del mundo indiano (Mora Mérida, 1980). Extendida en la Edad Media, adquirió un nuevo impulso a mediados del siglo XVI con el Concilio de Trento, el cual se empeñó en la obligación de los obispos de visitar cada año su diócesis, personalmente o a través del vicario general u otro visitador en caso de legítimo impedimento, a fin de «introducir la doctrina sana y católica, y expeler las herejías; promover las buenas costumbres y corregir las malas; inflamar al pueblo con exhortaciones y consejos a la religión, paz e inocencia, y arreglar todas las demás cosas en utilidad de los fieles» (El sacrosanto y ecuménico concilio de Trento, 1847, sesión XXIV, III). En América, las normas canónicas criollas se ocuparon de difundir la disciplina tridentina. A modo de ejemplo, en el III Concilio Limense (1582-1583), convocado por Toribio de Mogrovejo, se exhortaba encarecidamente a los obispos a practicar por sí mismos la visita y, en caso de nombrar visitadores, se les recomendaba que tuvieran especial cuidado al escogerlos. ${ }^{16}$

Ramón trata acerca de las clarisas que se desprenden del Monasterio de Antigua Fundación, las descripciones de dicho autor también son aplicables a nuestro caso, ya que las religiosas fundadoras del Monasterio de la Victoria traían hábitos del monasterio antiguo. Asimismo, el completo trabajo de Juan de Guernica, fundamentado en el archivo de esta nueva fundación, da cuenta de dicha situación (Guernica, 1944).

16 Véase: Tercer Concilio Limense (1583-1591), 2017. 
Por medio de la visita, el prelado conocía mejor a su pueblo y se enteraba del verdadero estado de su Iglesia (Oviedo Cavada, 1992, pp. 58-61). Su tarea implicaba una doble vertiente, tanto material como espiritual (Andreu Andreu, 1999, p. 222). La primera estaba dada por la Visitatio rerum, es decir, la obligación que tenía el prelado de constatar la situación de iglesias y cementerios, de exigir el inventario de bienes, de revisar la existencia y el estado de los ornamentos, libros y copias de documentos sinodales y conciliares, de informarse del pago del diezmo y, finalmente, de realizar inspecciones de conventos, monasterios, cofradías, hospitales y escuelas de su diócesis. La segunda se fundamentaba en la Visitatio hominum, que debía extirpar vicios y pecados públicos que ofendían a Dios y a la sociedad, poniendo su mirada en laicos y en sacerdotes. Sobre estos últimos se vigilaba, por ejemplo, el cumplimiento de su oficio y el testimonio de vida que llevaban. Asimismo, se revisaban los testamentos para observar si se cumplían las voluntades referidas a las obras pías (Acevedo, 2014).

Pese a la relevancia del obispo, en estas lejanas latitudes australes resultó común la participación de otros visitadores, debido a la edad avanzada de varios prelados y a la dificultad para recorrer amplias y agrestes geografías, como era el caso de la diócesis de Santiago durante los siglos XVII y XVIII. Las clarisas antiguas, por ejemplo, fueron visitadas a lo largo del siglo XVIII —además de por los obispos - por Francisco Martínez Aldunate, Pedro de Tula Bazán, Gregorio Eulogio Tapia y Josef Antonio Muñoz de Aldunate. ${ }^{17}$

17 Archivo del Monasterio de Clarisas de Antigua Fundación [MCAF], vol. 91, ff. 50-85. En general, los autos de dichas visitas contenían reparos y sugerencias vinculados a la observancia de la Regla de Santa Clara. Intentaron reglamentar la entrada y salida de seglares varones al claustro, así como el comportamiento, número y edad de las criadas que servían a las religiosas. Dentro de los informes también fueron comunes las menciones y regulaciones en torno al locutorio. En otro ámbito, se referían a aspectos temporales como los ingresos económicos 
Desde otra perspectiva, la visita pastoral permitía fortalecer la figura de los obispos y normar rigurosa y exhaustivamente, a través de ellas, tanto al clero como a los fieles (Candau Chacón, 1998). Esta institución también llenaba la exigencia vinculada al ejercicio del patronato regio. Por ello, al terminar la visita los prelados redactaban informes dirigidos al monarca, en los cuales se daba cuenta de todo lo que habían observado en sus diócesis, incluyendo sus más íntimas impresiones. En el caso de los monasterios femeninos, estos reportes eran denominados autos de visita y, para el caso particular de las clarisas antiguas de Santiago, gran parte de dicha documentación ha sido conservada en su archivo conventual.

Un profundo análisis del patrimonio documental de estas clarisas permite señalar que, al interior del monasterio, junto con la pobreza original, el silencio aconsejado para la vida religiosa se relajaba de diversas formas. Las amonestaciones de la jerarquía eclesiástica expresadas en sínodos y en las ya mencionadas visitas pastorales son elocuentes, pues demuestran cómo la mundanidad del ruido había penetrado en el claustro, contaminando un aspecto fundante de la espiritualidad franciscana femenina y que da sentido a la regla original, es decir, a la vida contemplativa y de oración.

En líneas generales, las principales infracciones al silencio de las monjas van de la mano con la violación de la clausura. Por una parte, existe una constante entrada y salida de seglares del convento, en distintos contextos; por otra, las mismas religiosas, tanto de coro como legas, abusan de las excepciones que terminan por entorpecer el recomendado retiro conventual. Así también, los seglares que han ido poco a poco poblando el monasterio — criadas, donadas, esclavos y peones - no permiten que el espacio se mantenga sin ruido, pues ellos no están obligados a la observancia religiosa que supone la profesión de votos.

del monasterio o el peligro de las vanidades del mundo, ejemplificado a través de la necesidad de vestir sobriamente. 
Similar era la situación en el resto de Hispanoamérica, tal como lo hemos señalado. Así lo expresa claramente Alicia Fraschina al referirse al caso de Lima, quien apunta que «en 1770 el arzobispo de Lima — ciudad con catorce conventos femeninos- Diego Antonio de Parada promulgó un auto de reforma, de tono moderado, en el que hace hincapié en el estricto respeto de la clausura - en especial la entrada y salida de sirvientes y seglares-, la defensa de la modestia, la necesidad de establecer con rigor las horas de silencio y desterrar la ostentación en las celebraciones religiosas» (Fraschina, 2008, p. 449).

En la misma línea, en el Reino de Chile, tanto los sínodos de los obispos Bernardo Carrasco y Saavedra (1688) y Manuel de Alday (1763) como las visitas pastorales, cuyas relaciones se encuentran en el archivo monástico, señalan cuáles eran las formas más comunes de obviar este mandato. A continuación, y de modo panorámico, se expondrán sucintamente las principales observaciones realizadas por los prelados recién mencionados.

El sínodo de 1688 se refiere a la perturbación del silencio en consideración de las epidemias y de las enfermedades que amenazaron a las clarisas y a sus acompañantes pues, bajo el pretexto de curar a las religiosas, se cometieron abusos al respecto, pasando el mundanal ruido de la ciudad al interior del monasterio (Sinodos Diocesanos del Arzobispado de Santiago de Chile, 1858, p. 48). Así lo afirma el acta del V Sínodo de Santiago, convocado por el dominico Carrasco, IX obispo de la diócesis:

El trabajo fatal de la Peste, que afligió a esta Ciudad el año pasado, no fue menos riguroso en los Monasterios; siendo preciso, para acudir al número grande de Enfermas, relajar algo la estrechez de la Clausura, dando Licencias a las Madres, y Deudas de las Religiosas, que entrasen á la curación, y cuidado de ella [...]. Por tanto encarga seriamente este Sínodo que, en adelante, los Prelados no sean fáciles a conceder Licencia, para entrar a los Monasterios con pretexto de curación, sino es en enfermedad muy grave, a que los Médicos no pueden concurrir con las 
medicinas de su Facultad, y sea necesaria la asistencia de alguna mujer, en que se las encarga la conciencia. ${ }^{18}$

En este sínodo se denuncian otras violaciones a la clausura y por ende al silencio, como las recreaciones que se llevaban a cabo en los locutorios. Estos espacios restringidos, que conectaban a las religiosas con las personas del exterior, eran habitaciones reservadas para la comunicación estrictamente necesaria y separaban, por medio de una reja — símbolo de la necesidad del aislamiento para la oración contemplativa-, a las monjas de sus visitantes. En consecuencia, el sínodo veta ciertas acciones que se daban frecuentemente en este intercambio social, tales como: «las representaciones de comedias, y coloquios», que realizaban las seglares en «trajes profanos» para las religiosas (Sinodos Diocesanos del Arzobispado de Santiago de Chile, 1858, p. 48).

Gran perturbadora del silencio era la música sin fines estrictamente litúrgicos y, más aún, los bailes, cuya práctica había sido aceptada por las religiosas en los locutorios. Al respecto, el obispo escribe: «no permitan se dé música en las puertas a ninguna persona de fuera, ni bailen en ellas, ni las Niñas de educación; porque es muy grande el desorden de Concursos, que se junta, así de los de fuera, como las de adentro, faltando al recogimiento interior del Monasterio, y a la modestia religiosa) (Sinodos Diocesanos del Arzobispado de Santiago de Chile, 1858, p. 48). No deja de llamar la atención la gravedad de este asunto, ya que incluso se amenaza con un castigo a la prelada - la priora del monasterio — que no cumpliera con la disposición referida. El sínodo especifica una «pena de cuatro meses de suspensión a la Prelada, que contraviniere a este mandato; y los dichos agasajos de músicas se podrán hacer en los Locutorios, sin bailes; y por ninguna suerte se hagan en la Iglesia: so la misma pena» (Sinodos Diocesanos del Arzobispado de Santiago de Chile, 1858, p. 48). Asimismo, el obispo Luis Francisco Romero, en su visita al

18 Sinodos Diocesanos del Arzobispado de Santiago de Chile (1858, p. 48). 
Monasterio de las Clarisas el 14 de septiembre de 1713, insiste en este aspecto y subraya específicamente que «no haya música» en la clausura. ${ }^{19}$ Por su parte, el señor provisor de monasterios, doctor don Gregorio Eulogio de Tapia y Zegarra, el 10 de mayo de 1771 consideraba «un abuso» que se cantara completamente el oficio divino, pues debía «alternarse» el rezo con el canto. La autoridad insistía en que este exceso era tan grave como rezar el oficio en la propia celda y no en el coro. ${ }^{20}$

Cabe señalar que bailes y fiestas son parte del entorno barroco que rodea a las religiosas del monasterio y cuyos muros, al parecer porosos, permean desde el exterior. Así entonces, el festejo en sí mismo anima a la comunidad religiosa y la puede acercar, en ciertas ocasiones, al mundo profano. No obstante, la religiosidad también requiere de las fiestas y el ciclo litúrgico se organiza en torno a los grandes acontecimientos de fe que se rememoran año tras año. En el caso de las clarisas, el 11 de agosto celebran a santa Clara con toda la pompa posible. La historiadora y especialista Isabel Cruz, al momento de recrear esta festividad, destaca la asistencia del cabildo de la ciudad a una misa solemne por la mañana y una procesión en la que, simbólicamente, el capellán del monasterio entregaba el estandarte al alférez real. Dicho ritual finalizaba con los dulces agasajos de las monjas y, en ocasiones, con la representación de obras de teatro ofrecidas a las autoridades, quienes compartían con la comunidad un momento de gran regocijo ${ }^{21} \mathrm{y}$, definitivamente, poco silencio (Cruz, 1995, pp. 166-167).

19 MCAF, vol. 91, ff. 8-9.

20 MCAF, vol. 91, ff. 109-112.

21 Isabel Cruz, en su completo estudio del año 1995, se sorprende de las omisiones al respecto en las fuentes vinculadas al cabildo. Sin embargo, el jesuita del siglo XVII Alonso de Ovalle entrega pistas concretas en su Histórica relación del Reino de Chile. Por su parte, el MCAF revela los costos de las fiestas. Las pomposas celebraciones que las religiosas desarrollaban en honor a santa Clara, durante el mes de agosto de cada año, quedan constatadas en diferentes documentos. Especialmente representativas son las fiestas de 1799 y 1800, las que registran un 
Junto con los festejos en torno a la fundadora de la orden, otras festividades relevantes eran Navidad, Pascua, san Francisco, o la Purísima (Cruz, 1995). Este tipo de actividades religiosas, tan cuestionadas por los obispos por su falta de sencillez, son un evidente obstáculo para la debida observancia del silencio (Sínodos Diocesanos del Arzobispado de Santiago de Chile, 1858, p. 50). Si bien para la tradición de la Iglesia el rito festivo resulta central, el cuestionamiento por parte de la autoridad se refería a los excesos a los que llegaban dichas celebraciones intramuros. Estas podían contar, incluso, con pirotecnia — así lo demuestra el archivo con la compra de pólvora- ${ }^{22} \mathrm{o}$ representaciones teatrales, situación que implicaba la estimulación de los sentidos, tan combatida por el modelo ascético-místico encarnado por santa Clara, cuyo referente parecía alejarse u omitirse en este tipo de eventos masivos. Conforme con ello, eran considerados peligrosos para la vida claustral y las amonestaciones iban en ese sentido. Sin embargo, las prácticas reveladas en la revisión documental del monasterio no proporcionan noticias de cambios significativos al respecto.

$\mathrm{Si}$ bien las fiestas eran ocasionales, los prelados dejan constancia en sus visitas al monasterio, durante el siglo XVIII, de la persistencia de las faltas al retiro conventual por parte de las religiosas. La gran cantidad de personas que convivían en el espacio claustral estaba muy vinculada a esta dificultad para guardar el debido silencio. A modo de ejemplo el obispo Luis Francisco Romero, al inspeccionar el monasterio en varias ocasiones $(1710,1713$ y 1716), cuestionaba la relajación de la clausura y la atribuye, en gran parte, a que las criadas, seglares y niñas educandas «hacen mucho ruido y murmullo». Lo mismo es advertido al poco tiempo, en 1721, por el obispo Alejo

gasto de 300 pesos de la época, aproximadamente (MCAF, vol. 65, ff. 19v-20). Cf. Leal Pino, de La Taille y Fuentes González (2019).

22 Registro de cuentas (octubre de 1683), MCAF, vol. 17, f. 35. 
Fernando de Rojas y Acevedo. Monseñor Alonso del Pozo, por su parte, mandó en 1725 que no se mezclasen seglares y religiosas a la hora de la oración, para así mantener el silencio necesario en ese momento, e incluso que las monjas rezaran a puerta cerrada para lograr el ambiente propicio para la comunicación con Dios. Monseñor González de Melgarejo, en 1745, restringe el número de criadas a un máximo de dos o tres por religiosa, y ordena que no se permitan niñas menores de cinco años como educandas, «por ser estas de gran perjuicio para el silencio tan necesario en esposas de Jesucristo, que han de tener sosiego en el Espíritu y recogimiento interior». El obispo Alday, a propósito de su visita pastoral al convento de Santa Clara de Antigua Fundación en el año 1756, insiste en la necesidad de no enseñar a bailar a las educandas ni de tocar instrumentos durante las horas de silencio. ${ }^{23}$

Setenta y cinco años después del sínodo de Santiago bajo el episcopado de Carrasco y Saavedra, el obispo Alday insiste nuevamente en las disposiciones de su predecesor, de un modo particular en aquellas que se refieren a las visitas de seglares a los locutorios del convento, pues este movimiento constante de personas afectaba de manera importante la correcta observancia de la norma del silencio. A partir de un lenguaje claro y preciso se puede entender que las religiosas no se han hecho cargo de las disposiciones de 1688 y, al respecto, se señala que:

[...] para que las Esposas de Jesucristo, con el retiro, logren el trato familiar de su Esposo, y vivan abstraídas de las Comunicaciones exteriores, mando: que las Abadesas no permitan Visitas frecuentes a las Religiosas; y que ninguna pase de las Ave Marías, porque a ese tiempo se han de cerrar las Puertas de los Locutorios, y la exterior del Monasterio: todo lo cual, aunque se observa, ha parecido, sin embargo, a este

23 El conjunto de las visitas pastorales se encuentra transcrito en el MCAF, conservado en la Universidad de los Andes, Chile. 
Sínodo, recomendarlo nuevamente; para que las Preladas acentúen su Celo, así en la guarda de la Clausura, como en el cuidado de evitar la frecuencia de Visitas, y que no pasen del tiempo señalado. ${ }^{24}$

A lo largo del siglo XVIII las visitas pastorales insisten en este punto, lo cual demostraría la falta de acatamiento a la norma y el consecuente peligro para la fecundidad de una vida consagrada. El obispo Francisco José Marán, en 1795, recuerda a las religiosas la importancia del silencio en los siguientes términos:

Los santos fundadores de las religiones lo consideraron como la piedra fundamental de la vida religiosa, lo dejaron sumamente encargado, y dispusieron que se guardase con mucho cuidado en los claustros, dormitorios y demás oficinas de los conventos; de tal suerte que muchos varones experimentados y de gran espíritu han creído que para reformar una Religión bastaría reformarla en silencio. ${ }^{25}$

Así pues, si bien no resulta difícil suponer la inobservancia en la práctica de esta virtud inherente a la contemplación del claustro, llama la atención la resistencia por parte de la comunidad religiosa frente a las recomendaciones y prescripciones, tanto de la regla como de las autoridades eclesiásticas de la diócesis. Al parecer, las monjas no se sentían en falta a pesar de las constantes reprimendas, pues continuaban con sus prácticas y, aparentemente, no tomaban medidas concretas — muchas de ellas sugeridas por las autoridades - a fin de subsanar este gran problema para la contemplación. Claramente, el contexto barroco que rodea al monasterio, la sociabilidad en torno a la comunidad conventual y el interés urbano por contar con espacios de este tipo, contribuyeron a la permanencia de estos excesos que, consecuentemente, van en contra de la vida de las vírgenes consagradas según el modelo de santa Clara de Asís y de la tradición ascético-cristiana, desde el siglo IV en adelante.

24 Sínodos Diocesanos del Arzobispado de Santiago de Chile (1858, pp. 218-219).

25 Visita del obispo Francisco José Marán, 1796, MCAF. 
Ahora bien, resulta particularmente ilustrador que, a lo largo del siglo XIX, las visitas episcopales siguieron reparando en el cuidado del silencio como uno de los tópicos fundamentales a la hora de custodiar la clausura propiamente dicha. No debe sorprender que los prelados José Santiago Rodríguez Zorrilla, Manuel Vicuña y Rafael Valentín Valdivieso hayan enfatizado en la necesidad de la vida retirada para lograr una mejor aproximación y dedicación al espíritu de la regla. Monseñor Valdivieso apunta, de manera particular, a las mismas desobediencias referidas por sus predecesores (Serrano, 2009, p. 522). Él señala cómo el número de seglares y criadas, lejos de disminuir, ha seguido en aumento y da cuenta de las múltiples visitas que se multiplican dentro del locutorio, resultando perjudiciales desde todo punto de vista para su deber de estado, pues hacen «difícil el recogimiento tranquilo de la oración» y dificultan a las religiosas el ideal propuesto de «consagrarse al servicio del Señor en la soledad de los claustros». Por lo mismo, el obispo propuso una nueva reglamentación de acuerdo con la abadesa de turno, para así sistematizar las visitas y normar la cantidad de personas que debían morar dentro de los muros conventuales. En este régimen de observancia prohíbe, además, que las asiladas seglares pasen sin licencia de la abadesa «al claustro de las religiosas y se encarga a la prelada que no sea fácil entregar esta licencia»». ${ }^{26}$ Con relación a este punto, el prelado escribe:

Siendo graboso a la comunidad el excesivo número de hermanas legas de o velo blanco, retardando al mismo tiempo las mejoras en la observancia regular a que la comunidad aspira porque acrecienta el número de relihgiosas al paso que disminulle [sic] las dotes que se contribuyen al monasterio para su subsistencia, ya que no sea posible reducir el número de las dichas hermanas al de una por cada dies [sic] de coro o sea de velo negro como lo prebienen [sic] las constituciones de la Orden a causa de la multitud de oficios que deben servir, se ordena: que por ahora no excedan de treinta las dichas hermanas de velo blanco que tenga el

26 Decretos dictados por el Vicario General el 12 de noviembre 1874, MCAF. 
monasterio; prohibiendo que en adelante se de ábitos [sic] de esta clase hasta que el número de las dichas religiosas de velo blanco no quede reducido a las treinta que ahora se fijan; imponiendo como se impone presepto [sic] de santa obediencia a la Reverenda Madre Abadesa que al presente lo es y las que en adelante lo sean para que no alimenten la esperanza de las pretendientes que aspiren ocupar huecos que excedan del número prefijado ni soliciten del prelado dispensa de este estatuto. ${ }^{27}$

De cualquier forma, estas conductas podrían considerarse parte de un proceso de adaptación de la regla al ámbito local, algo común en la América española, como lo ha manifestado Asunción Lavrin en su amplísimo trabajo para el caso mexicano. ${ }^{28}$ Dicha situación lleva a cuestionarse si la relajación antes referida permitiría explicar, en parte, el rol transformador del monasterio en cuanto espacio de sociabilidad y de intercambio ya desde finales del siglo XVII. Tanto en el periodo colonial como en el inicio del republicano, las fuentes arrojan una población de casi medio millar de personas al interior del convento de clarisas antiguas, ${ }^{29}$ cifra que no parecería excesiva para el Reino de Chile de acuerdo con el testimonio de Juan José de Santa Cruz, miembro de la expedición Malaspina (s. XVIII), quien menciona un universo de unas cuatrocientas personas en el convento de La Cañada (Sagredo y González, 2004, p. 474).

De todos modos, para el caso de Santiago el convento se habría posicionado como una suerte de foco cultural y de microcosmos que estaría mostrando una realidad femenina poco estudiada, debido a los trabajos que se realizaban al interior del monasterio como, por ejemplo, la repostería que pervive hasta hoy, además de la

27 Visita del obispo Rafael Valentín Valdivieso, 1846, MCAF.

28 Al respecto véanse Lavrin (1965, 1993 1995, 2016, pp. 160-193).

29 Véase nota 14. Si tenemos como punto de comparación la Orden de las Carmelitas Descalzas, el balance resulta diferente pues, al igual que en el resto de Hispanoamérica, en el Reino de Chile ellas representaban un caso singular. Debido a la reforma de la orden realizada por santa Teresa de Jesús, las profesas solo podían ser trece. Dicho número con el tiempo se amplió hasta veintiuno. 
cerámica que tuvo extendida circulación. Sorprende leer las referencias al contacto de las monjas con las autoridades civiles y religiosas, con los donantes masculinos que ingresaban al monasterio, con los grupos medios de artesanos y con gente del pueblo como peones, indios, esclavos y vagabundos. Estos últimos constituían un grupo de relevancia y vinculante con el mundo. Más específicamente, y tal como lo ha demostrado Alejandra Fuentes González, «además de los esclavos de origen africano que servían de manera particular a las monjas en sus celdas, el Monasterio Antiguo de Santa Clara tuvo durante el siglo XVIII esclavos que servían a todas las monjas del claustro en colaboración de indígenas, negros libres o mestizos» (Fuentes González, 2018, p. 133).

El trabajo colaborativo de todos estos actores que salían al mundo constantemente, así como la necesidad de contar con ellos para oficios como carpintería, albañilería, pintura y sastrería, permitió vincular esta institución femenina y de clausura con la incipiente labor artístico-gremial de la época colonial (Pereira Salas, 1965, p. 23). Así, su presencia y necesidad de fuerza de trabajo y acompañamiento no solo iba en contra del ideal del silencio de la orden y de la autoridad eclesiástica, sino que llevaba a que estos actores que participaban de un lugar de sociabilidad, que por definición era de clausura, contribuyeran a que este se tornara altamente permeable y con los consabidos riesgos que significaba para la vida consagrada (Fuentes González, 2018, p. 135).

La vida bajo la Regla de Santa Clara proporciona a las mujeres, asimismo, un acceso a la lectura, a la escritura y al conocimiento general, condición de privilegio que en el mundo exterior se ve limitada por el acotado rol hogareño y familiar otorgado al mundo femenino. ${ }^{30}$ Tras los muros conventuales existe además una amplia

30 Un claro ejemplo del privilegio intelectual que se abría en la clausura femenina es el caso de la vida y obra de la insigne escritora Sor Juana Inés de la Cruz (1648-1695) (Paz, 1982). De acuerdo con los registros documentales de los mo- 
posibilidad de trabajo, tanto en el ámbito del servicio doméstico, de la compañía y de las labores manuales y artesanales, lo que paradójicamente fortalece la presencia de este centro religioso dentro de la ciudad. Por todo esto, las familias, tanto de élite como de menor peso social, ven en la vida consagrada de sus hijas un atractivo importante que supondría, incluso, la posibilidad de un ascenso en el entramado de la sociedad de la época.

De esta forma, la relevancia del monasterio, a pesar de la clausura nominal, traspasa los distintos grupos y concreta los vínculos con el mundo exterior, lo que podríamos considerar como uno de los motivos que explicarían el florecimiento cultural que ha permanecido, al menos por cuatro siglos, en su particular práctica de elaboración de cerámica perfumada y su presencia clave en la tradición repostera chilena. ${ }^{31}$ La conocida influencia de esta comunidad de mujeres va desde los más importantes intereses económicos ${ }^{32}$ hasta

nasterios chilenos de la época colonial, no se conocen aún personalidades como la de la monja novohispana. Las únicas escritoras reconocidas por la historiografía hasta el momento son: Úrsula Suárez (1666-1749), religiosa clarisa de la Victoria que redactó su Relación autobiográfica; Dolores Peña y Lillo (1739-1823), dominica y autora del epistolario editado por Raïssa Kordic: Epistolario de Sor Dolores Peña y Lillo (Chile, 1763-1769) (2008); Tadea García de la Huerta (†1827), monja carmelita del Monasterio del Carmen de San Rafael, autora de: Relación de la inundación que bizo el río Mapocho de la ciudad de Santiago de Chile, en el Monasterio de Carmelitas, Titular de San Rafael, obra impresa en Lima, probablemente en 1784.

31 Las Clarisas de Antigua Fundación destacan por la elaboración de las cerámicas perfumadas por cuatro siglos, las cuales fueron exportadas a España y al resto de América. Véase Cruz, de La Taille y Fuentes González (2019).

32 Abundantes son los volúmenes del archivo de las clarisas antiguas que registran los censos, figura económica clave en los vínculos del monasterio con el mundo. Específicamente, la documentación se refiere al censo consignativo, es decir, a préstamos de dinero que se realizaban mediante una transacción contractual privada entre una persona o institución (censualista, acreedor o prestamista) y un censuario (prestatario o deudor). En dicho contrato, el préstamo o adquisición del capital se garantizaba mediante el gravamen de un bien (terreno o inmueble), el cual se imponía a censo en favor de la institución eclesiástica y por el cual esta recibía una pensión anual. Los volúmenes 17-32 del MCAF están dedicados a 
el albergue de las donadas — mujeres desprovistas de lazos familiares y de bienes materiales - que se ofrecían al monasterio porque no tenían ninguna pertenencia en la vida extramuros, donde a veces eran rechazadas o simplemente se les ignoraba.

\section{ConClusión}

Al momento de concluir, nos atrevemos a sugerir que el caso concreto de la denunciada relajación en el cuidado y la observancia del silencio constituye solo una muestra de un modo de vida aparentemente alejado de la regla original de la orden por parte de las Clarisas de Antigua Fundación en Chile, de acuerdo con los registros documentales de la jerarquía eclesiástica. No obstante, esta misma relajación testimoniada por las autoridades entre 1678 y 1860 habría logrado posicionar a la orden como una de las más influyentes en la ciudad de Santiago, tanto en el ámbito social, cultural y económico. A pesar de haber suscitado una serie de críticas normativas de control y disciplina por parte de la jerarquía eclesiástica de la diócesis, el impacto de las relaciones con el exterior dejó huellas en la vida cotidiana de la capital. El convento pasó a ser, incluso, una posibilidad de contacto y de redes sociales, tanto para las mujeres de élite como para las de grupos socialmente vulnerables y, más sorprendente aún, para hombres, como fue el caso de indios y esclavos.

En suma, el análisis de las visitas pastorales y la relectura de los sínodos de los siglos XVII y XVIII dan noticia de un fenómeno histórico más o menos habitual en la América española, pues

este asunto en particular. Dentro de los documentos se encuentran, por ejemplo: el número de caso con la información del censuario, el monto del principal y los réditos (como, por ejemplo, si estos se han pagado o no), escrituras de imposición, documentos de sucesión de tierras, causas ejecutivas, solicitudes de embargo, remates, tasaciones, entre otros. Además, se puede encontrar algunos censos relativos al pago de dotes de religiosas y gastos de profesión. 
el cuidado del silencio por parte de las clarisas y la confrontación de las prácticas de las monjas chilenas con la regla del siglo XIII y los escritos de la santa fundadora, santa Clara de Asís, evidencian parte de las múltiples variantes y transgresiones que experimenta la observancia de las normas en el país. Las autoridades eclesiásticas no observaron ningún progreso al respecto sino, por el contrario, amonestaron a lo largo de los años, y de manera vehemente, las prácticas heterodoxas en las que perseveraron estas religiosas, sin ningún resultado positivo.

Esta versatilidad antinómica de la clausura, si bien significó la transgresión de delicados límites en los votos monásticos que motivaron a la jerarquía a corregir e intervenir, implicó, desde el otro lado de la balanza y del muro, la oportunidad de una vida estable para un gran número de personas, cuya cifra exacta se encuentra aún lejos de calcularse. Aunque ruidosas y heterodoxas, las clarisas constituyeron un enclave seguro y de gran tradición histórica en el centro de Santiago de Chile. Los cambios propios de la modernidad y la disposición urbana del siglo XX alejaron el mundo monástico femenino del casco histórico de la ciudad; en este nuevo emplazamiento la vida monástica ha tenido consecuencias efectivas para el silencio sin fin profesado en el legendario convento de San Damián, asumido por las clarisas del Monasterio de Santa Clara de Antigua Fundación de Santiago de Chile. ${ }^{33}$

\section{REFERENCIAS}

\section{FUENTES PRIMARIAS}

Archivo del Monasterio de Clarisas de Antigua Fundación [MCAF] (Universidad de los Andes, Chile)

33 El monasterio ubicado en la comuna de Puente Alto, en Santiago, sufrió graves daños después del terremoto de 2010 y cerró sus puertas, de manera definitiva, en 2018. La comunidad que lo habitaba se trasladó a otros dos conventos de la orden en Chile, ubicados en las comunas de La Florida y Los Ángeles. 


\section{FUENTES SECUNDARIAS}

Acevedo, Alba María (2014). «Visitar para conocer. Conocer para reformar: las visitas de los obispos de Santiago de Chile a Cuyo a comienzos del siglo XVIII (1700-1730)». Épocas. Revista de Historia, núm. 10, pp. 9-31.

Andreu Andreu, Antonio (1999). «La Visita Pastoral como instrumentum laboris en la cura animarum de la diócesis de Cartagena. Una visión histórica desde la Edad Moderna hasta nuestros días a través de los mandatos de visita». Scripta Fulgentina. Revista de teología y bumanidades, núm. 18, pp. 219-256.

Arenas Frutos, Isabel (2005). «Las “otras" niñas y criadas ante la reforma conventual femenina en México y Puebla de los Ángeles». En: Jesús Paniagua Pérez (coord.). España y América entre el Barroco y la Ilustración (1722-1804). León: Publicaciones Universidad de León, pp. 191-210.

Burns, Kathryn (1999). Colonial Habits: Convents and the Spiritual Economy of Cuzco, Peru. Durham: Duke University Press.

Candau Chacón, María Luisa (1998). «Instrumentos de modelación y control: el Concilio de Trento y las visitas pastorales (la Archidiócesis Hispalense, 1548-1604)». En: José Martínez Millán (dir.). Felipe II (1527-1598): Europa y la monarquía católica, vol. III. Madrid: Parteluz. pp. 159-177.

Cruz de Amenábar, Isabel (1995). La fiesta. Metamorfosis de lo cotidiano. Santiago: Ediciones UC.

Cruz de Amenábar, Isabel, Alexandrine de La Taille y Alejandra Fuentes González (2019). Cerámica perfumada de las monjas clarisas. Desde Chile hacia el mundo. Oficio, terapéutica y consumo, siglos XVI-XX. Santiago: Ediciones UC.

Deusen, Nancy van (2007). Entre lo sagrado y lo mundano. La práctica institucional y cultural del recogimiento en la Lima virreinal. Lima: Pontificia Universidad Católica del Perú; Instituto Francés de Estudios Andinos. 
El Arca de Tres llaves. Crónica del Monasterio de Carmelitas Descalzas de San José, 1690-1990 (1989). Santiago: Editorial Cochrane.

El sacrosanto y ecuménico concilio de Trento (1847). Barcelona: Imprenta de Ramón Martín Indar.

Fontecilla Larraín, Arturo (1943). «Recuerdos del Antiguo Monasterio de las Monjas Capuchinas». Boletín de la Academia Chilena de la Historia, núm. 27, pp. 77-93.

Fraschina, Alicia (2008). «Reformas en los conventos de monjas de Hispanoamérica, 1750-1865: cambios y continuidades». Hispania Sacra, Madrid, vol. 60, núm. 122, pp. 445-466.

Fraschina, Alicia (2010). Mujeres consagradas en el Buenos Aires colonial. Buenos Aires: Eudeba.

Fuentes GonzÁlez, Alejandra (2018). «El claustro femenino como microcosmos laboral en Hispanoamérica: los esclavos negros y afromestizos del Monasterio Antiguo de Santa Clara. Santiago, Chile (siglo XVIII)». Itinerantes. Revista de Historia y Religión, Tucumán, núm. 9, pp. 123-142.

Fuentes GonzÁlez, Alejandra (2019). Entre la oración contemplativa y el trabajo de sus manos: clausura femenina y prácticas laborales en el Monasterio Antiguo de Santa Clara de Santiago, 1678-1825. Tesis de doctorado. Santiago: Universidad de los Andes.

Guarda, Gabriel (2016). La Edad Media en Chile. Historia de la Iglesia. Desde la fundación de Santiago a la incorporación de Chiloé. 1541-1826. Santiago: Ediciones UC.

Guernica, Juan de (1944). El Monasterio de Clarisas de Nuestra Señora de la Victoria en sus cuatro periodos. Santiago: Editorial Sagrado Corazón de Jesús.

Iriarte, Lázaro (1979). Historia franciscana. Valencia: Asís. 
Kordic, Raïssa (2008). Epistolario de Sor Dolores Peña y Lillo (Chile, 1763-1769). Madrid; Fráncfort: Iberoamericana-Vervuert.

La provincia eclesiástica chilena: erección de obispados y división en parroquias (1895). Friburgo: Casa Editorial Pontificia de B. Herder.

Lainati, Chiara Augusta (2004). Santa Clara de Asís: contemplar la belleza de un Dios esposo. Madrid: Ediciones Encuentro.

Lavrin, Asunción (1965). «Ecclesiastical Reform of Nunneries in New Spain in the Eighteenth Century». The Americas, vol. 22, pp. 182-203.

Lavrin, Asunción (1993). «Religiosas». En: Louisa S. Hoberman y Susan M. Socolow (comps.). Ciudades y Sociedad en Latinoamérica Colonial. Buenos Aires: Fondo de Cultura Económica, pp. 175-213.

Lavrin, Asunción (1995). «De su puño y letra: epístolas conventuales». En: Manuel Ramos Medina (coord.). El monacato femenino en el imperio español. Monasterios, beaterios, recogimientos y colegios. Ciudad de México: Condumex, pp. 43-61.

Lavrin, Asunción (2016). Las esposas de Cristo. La vida conventual en la Nueva España. Ciudad de México: Fondo de Cultura Económica.

Leal Pino, Cristián, Alexandrine de La Taille y Alejandra Fuentes GonzÁLEZ (2019). «Pobreza franciscana y economía monástica: prácticas cotidianas de frailes y monjas en Santiago de Chile (1790-1820)». Anuario de Historia de la Iglesia, vol. 28, pp. 319-341.

Loreto López, Rosalva (2000). Los conventos femeninos y el mundo urbano de la Puebla de los Ángeles del siglo XVIII. Ciudad de México: El Colegio de México.

Martínez Cuesta, Ángel (1995). «Las monjas en la América Colonial 1530-1824». Thesaurus. Boletín del Instituto Caro y Cuervo, vol. 50, pp. 572-626. 
Millar Carvacho, René (2013). «Las hagiografías y los procesos de canonización como fuentes para la historia de la religiosidad en la América Hispana». Revista de Historia, Concepción, núm. 20, pp. 137-145.

Millar Carvacho, René y Carmen Gloria Duhart (2005). «La vida en los claustros. Monjas y frailes, disciplinas y devociones». En: Rafael Sagredo y Cristián Gazmuri (eds.). Historia de la vida privada en Chile. Tomo I. El Chile tradicional. De la Conquista a 1840. Santiago: Taurus, pp. 125-159.

Mora Mérida, José Luis (1980). «La visita eclesiástica como institución en Indias». Anuario de Historia de América Latina, vol. 17, pp. 59-67.

Muñoz Olave, Reinaldo (1926). Las monjas trinitarias de Concepción: 1570-1822: Relato histórico. Santiago: Imprenta de San José.

Omaechevarría, Ignacio (1970). Escritos de Santa Clara y documentos contemporáneos. Madrid: Biblioteca de Autores Cristianos.

Ovalle, Alonso (1969). Histórica relación del Reino de Chile y de las misiones y ministerios que ejercita en él la Compañia de Jesús. Santiago: Instituto de Literatura Chilena.

Oviedo Cavada, Carlos (dir.) (1992). Episcopologio chileno. 1561-1815. Santiago: Ediciones UC.

Palacios RoA, Alfredo (2017). Breve historia del Monasterio de Santa Clara de Antigua Fundación (1567-1913). Valparaíso: Ediciones Universitarias de Valparaíso.

PAz, Octavio (1982). Sor Juana Inés de la Cruz o las trampas de la fe. Ciudad de México: Fondo de Cultura Económica.

Peña Otaegui, Carlos (1951). Una crónica conventual. El monasterio de las Agustinas de Santiago (1574-1951). Santiago: El Imparcial.

Pereira Salas, Eugenio (1965). Historia del arte en el reino de Chile. Santiago: Ediciones de la Universidad de Chile. 
Prieto, Luis Francisco (1911). Crónica del Monasterio de Capuchinas. Santiago: Imprenta de San José.

Ramón, Armando de y José Manuel Larraín (1982). Orígenes de la vida económica chilena. 1659-1808. Santiago: Centro de Estudios Públicos.

Rassam, Joseph (2017). Le silence comme introduction à la métaphysique. París: Artège Lethielleux.

Rodríguez NúÑEz, Clara (1996). «El conventualismo femenino: las Clarisas». En: J. I. de la Iglesia Duarte, F. J. García Turza y J. Á. García de Cortázar (coords.). VI Semana de Estudios Medievales. Logroño: Instituto de Estudios Riojanos, pp. 87-100.

SAgredo, Rafael y José Ignacio GonzÁlez (2004). La Expedición Malaspina en la frontera austral del imperio español. Santiago: Editorial Universitaria; Centro de Investigaciones Barros Arana.

Serrano, Sol (2009). «El ocaso de la clausura. Mujeres, religión y Estado nacional. El caso chileno». Revista Historia, núm. 42, pp. 505-535.

Sinodos Diocesanos del Arzobispado de Santiago de Chile celebrados por los ilustrísimos señores Doctor don Frai Bernardo Carrasco Saavedra i Doctor don Manuel de Aldai i Aspee (1858). Nueva York: Eduardo Dunigan i Hermano.

SuÁreZ, Úrsula (1984). Relación autobiográfica. Santiago: Biblioteca Antigua Chilena; Academia Chilena de la Historia.

Tercer Concilio Limense (1583-1591) (2017). Lima; Roma: Universidad Pontificia de la Santa Cruz; Facultad de Teología Pontificia y Civil de Lima; Ediciones San Pablo.

Triviño Monrabal, María Victoria (2011). «El libro que da forma a la vida claustral: la Regla de Santa Clara, en los 800 años de la fundación de las Clarisas (1212-2012)». En: Francisco Javier Campos (coord.). La clausura femenina en el mundo bispánico: una fidelidad secular. San Lorenzo del Escorial: Real Centro Universitario EscorialMaría Cristina, pp. 425-448. 


\section{Agradecimientos}

Este trabajo es resultado del Proyecto «Rescate y Difusión del Archivo de Santa Clara de Antigua Fundación», llevado a cabo por el Instituto de Historia de la Universidad de los Andes, Chile, gracias al apoyo del Programa David Rockefeller Center for Latin American Studies (Harvard University, 2013-2015).

Fecha de recepción: 11 de enero de 2021. Fecha de evaluación: 24 de marzo de 2021.

Fecha de aceptación: 11 de mayo de 2021.

Fecha de publicación: 1 de noviembre de 2021. 